\title{
Basic Characteristics and Survival Outcomes of Asian-American Patients with Clear Cell Renal Cell Carcinoma and Comparisons with White Patients: A Population-Based Analysis
}

\author{
Xiao $\mathrm{Li}^{1, *}$ \\ Zicheng $\mathrm{Xu}^{1, *}$ \\ Ting $X u^{1, *}$ \\ Feng Qi $\mathbb{D}^{\prime}$ \\ Ninghong Song ${ }^{2}$ \\ 'Department of Urology, The Affiliated \\ Cancer Hospital of Nanjing Medical \\ University \& Jiangsu Cancer Hospital \& \\ Jiangsu Institute of Cancer Research, \\ Nanjing, 210009, People's Republic of \\ China; ${ }^{2}$ Department of Urology, The First \\ Affiliated Hospital of Nanjing Medical \\ University, Nanjing, 210029, People's \\ Republic of China
}

*These authors contributed equally to this work

Correspondence: Feng Q

Department of Urology, The Affiliated Cancer Hospital of Nanjing Medical University \& Jiangsu Cancer Hospital \& jiangsu Institute of Cancer Research, Nanjing, 210009, People's Republic of China

Email qf199408@I63.com

Ninghong Song

Department of Urology, The First Affiliated Hospital of Nanjing Medical University, Nanjing, 210029, People's Republic of China

Email songninghong@I26.com
Background: To explore the baseline characteristics, pathological and survival outcomes of Asian-American patients with clear cell renal cell carcinoma (ccRCC), and make comparisons with White patients.

Materials and Methods: In this study, patients diagnosed with ccRCC between 2010 and 2015 were extracted from the Surveillance, Epidemiology, and End Results (SEER) database. Basic characteristics of Asian-American patients were analysed and compared with White patients. Then, proportional mortality ratio (PMR) analyses were performed in Asian population to investigate the proportions of different cause of deaths (CODs), and make comparisons with White patients. Moreover, Kaplan-Meier (KM) analyses were developed to investigate the survival disparities of ccRCC patients between AsianAmericans and White patients. Finally, a competing risk regression model was constructed to identify potential prognostic factors for ccRCC patients in the whole population.

Results: A total of 1586 Asian-American patients were eventually identified, and the median age at diagnosis was 61 years old. In Asian patients, those from South Asian had the youngest age at diagnosis $(\mathrm{P}<0.001)$ and the earliest stage of diseases (localized: $76.83 \%$, T1: $70.73 \%$, all $\mathrm{P}<0.05$ ) when compared with other ethnicities. No significant differences were detected in tumor characteristics between Asian-Americans and White patients. Older age $(\mathrm{P}<0.001)$, earlier stage $(\mathrm{P}<0.001)$ and the administration of surgery $(\mathrm{P}=0.050)$ were tightly associated with a lower risk of dying of RCC in Asian-American patients. Additionally, Asian-American patients had comparable survival outcomes when compared with White patients. Lastly, competing risk regression model revealed that age at diagnosis $(\mathrm{P}<0.001)$, tumor grade $(\mathrm{P}<0.001)$, histological stage $(\mathrm{P}<0.001)$, median household income $(\mathrm{P}<0.001)$ and the administration of surgery $(\mathrm{P}<0.001)$ were prognostic factors for cancerspecific survival (CSS) in ccRCC patients, while died of other causes was regarded as a competing event.

Conclusion: Asian-American patients had similar tumor characteristics and survival outcomes with White patients. In Asian patients, those from South Asian had the youngest age at diagnosis and the earliest stage of diseases. Age, grade, histological stage, household income and surgery were identified to be closely related to CSS in ccRCC patients. In the future, prospective and well-designed studies are needed to verify our findings.

Keywords: ccRCC, Asian-American, SEER, White, prognosis 


\section{Introduction}

Kidney cancer is the third most common malignant tumor in the genitourinary system, second only to prostate cancer and bladder cancer, ${ }^{1}$ accounting for $2.2 \%$ of all malignant tumors. The incidence rate of kidney cancer varies substantially worldwide, ranging from $0.1-15.3$ per 100,000 person-years. ${ }^{2}$ Early stage RCC patients have better survival outcomes and can be successfully treated by surgery or ablation, ${ }^{3}$ while up to one third of cases are metastatic at diagnosis or will develop to metastasis. ${ }^{4}$ Generally, the prognosis of metastatic RCC is very poor, and the 5 -year survival rate is less than $10 \%{ }^{5}$

Many studies have reported the racial and ethnic disparities of kidney cancer patients in incidence rates, clinical characteristics and prognosis. Compared with Whites, African Americans with ccRCC had lower VHL inactivation frequency, abundant $\mathrm{ccB}$ molecular subtypes and reduced up-regulation of HIF-related gene signals. These gene mutations indicated that African American patients with ccRCC were less sensitive to VEGF targeted therapy, and were risk factors for poor prognosis. ${ }^{6}$ Batai et $\mathrm{al}^{7}$ found that Hispanic American patients had significant younger age at RCC diagnosis than European American patients. In Hispanic Americans, patients with older age and Spanish native speaking were more likely to experience late stage RCC. Moreover, some other studies have well demonstrated the racial disparities of kidney cancer between White and Black patients. ${ }^{8-11}$ However, there are few studies on ccRCC in Asian populations, and most of these studies are single-center, small sample or retrospective. ${ }^{12,13}$

In addition, most high-quality references included in the clinical practice guidelines (NCCN, EAU) were from European and American countries, and mainly included White patients. Therefore, we extracted patients diagnosed with ccRCC between 2010 and 2015 from the SEER database to explore the baseline characteristics, pathological and prognosis of Asian American patients with ccRCC, and make comparisons with White patients.

\section{Materials and Methods Database}

All data were collected retrospectively from the SEER database. It is a public, population-based database, which records the incidence, basic information, treatment methods and prognosis of cancer patients in the United States since 1975. So far, it has covered about $34.6 \%$ of the US population (https://surveillance.cancer.gov/statistics/types/ race_ethnic.html) and is currently the largest cancer database worldwide. Additionally, approval for this study was obtained from the Ethics Committee of Jiangsu Cancer Hospital. Authors have signed the data-use agreement and got permission from SEER program to use this data.

\section{Patient Identification}

The "Case Listing Session" function in SEER*Stat software was applied to screen out patients diagnosed with ccRCC between 2010 and 2015. Inclusion criteria: (1) patients were confirmed as ccRCC with positive histology (C74.9, ICD-O: 8310/3) (2) year of diagnosis was from 2010 to 2015 , (3) ccRCC was the only malignancy of each patient, (4) patients with complete dates of survival. Moreover, patients who met any of the following should be excluded: (1) patients with unknown laterality or bilateral tumors, (2) patients with missing or ineligible data in race/ethnicity, TNM stage, marital and insurance status, household income, cause of death (COD), (3) patients were not Asians or Whites, (4) reporting source being autopsy/death certificate only. The selection flowchart is shown in Figure 1.

\section{Clinical Characteristics}

We extracted the baseline characteristics and pathological long-term survival outcomes of enrolled patients using the SEER*Stat software, variables including race/ethnicity, age at diagnosis, sex, year of diagnosis, primary site, histologic type, tumor grade, tumor laterality, diagnostic confirmation, SEER histological stage, AJCC 7th ed TNM stage, surgery, vital status, survival time, COD, insurance and marital status, sequence number, household income and so on.

In this study, we only included White patients and Asian patients in the United States. Asian patients were further divided into four groups: Chinese, Japanese, South Asian (Asian Indian, Pakistani and Asian Indian or Pakistani) and other Asian (Filipino, Korean, Laotian, Thai, Hmong, Kampuchean, Vietnamese). Hispanic was not removed from the White patients because we only divided enrolled patients on the basis of race/ethnicity rather than origin recode (including Non-Hispanic White, Non-Hispanic Black, Non-Hispanic Asian or Pacific Islander, Non-Hispanic American Indian/Alaska Native and Hispanic). Insurance status was defined as insured, uninsured and any Medicaid. Marital status was categorized into never married, married and SDW (including 


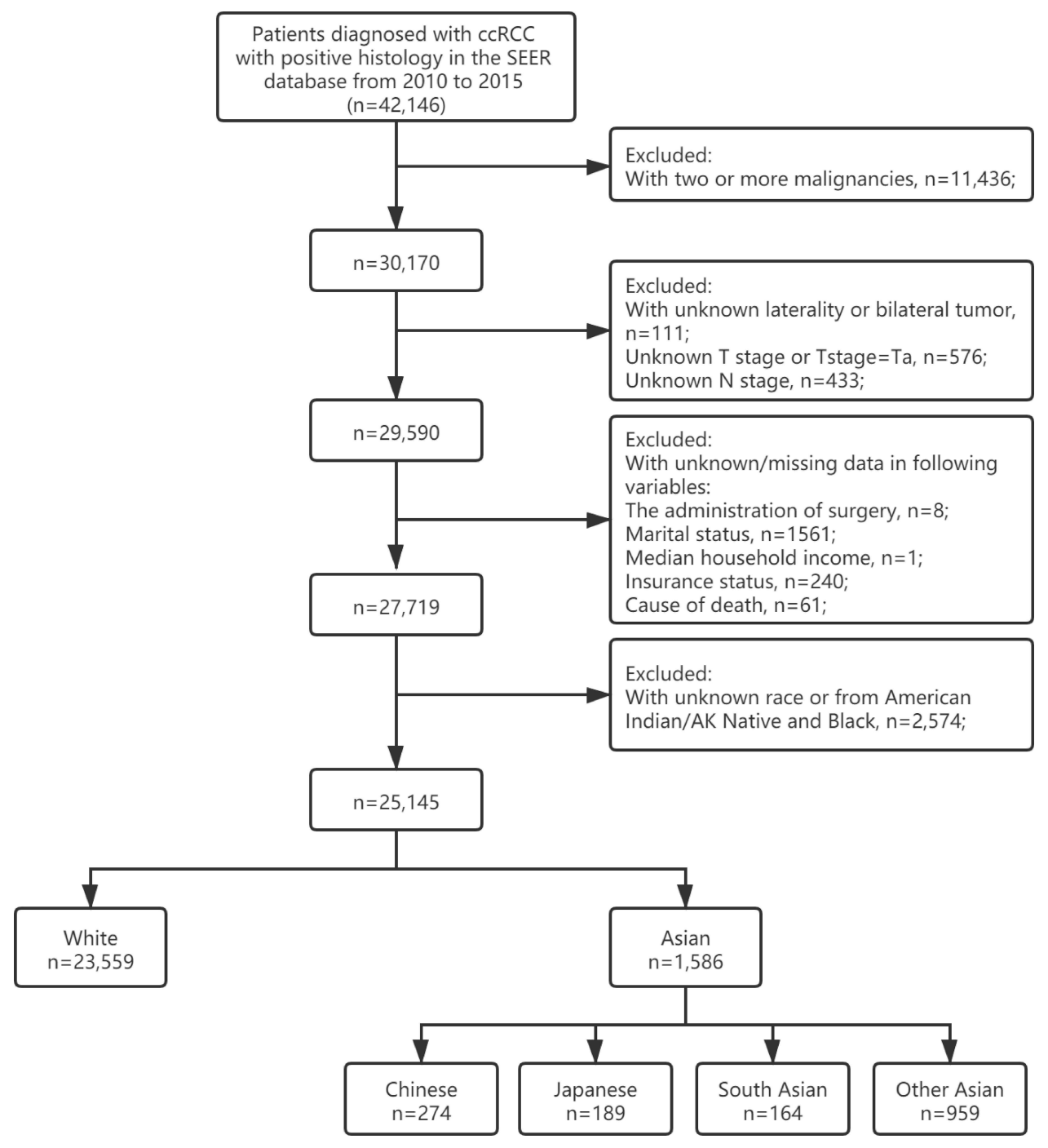

Figure I Flowchart of patient selection.

separated, divorced and widowed). In addition, the household income was divided into low and high levels according to the median value.

Previous studies have reported on the association between kidney cancer and risk factors such as smoking, ${ }^{14}$ obesity, ${ }^{15}$ and hypertension. ${ }^{16}$ Moreover, cancer survivors have an increased risk of cardiovascular disease (CVD) due to the shared lifestyles or toxicities of cancer treatment. ${ }^{17,18}$ Therefore, in this study, COD was mainly divided into three categories: died of ccRCC, died of CVD and died of other causes. Moreover, in order to balance the basic characteristics between Asian and White patients, we performed propensity score matching (PSM) analysis with a ratio of $1: 3$ using the nearest neighbor matching method. Variables utilized for PSM analysis included age at diagnosis, sex, tumor grade, laterality, histological stage, $\mathrm{T}$ stage, $\mathrm{N}$ stage, $\mathrm{M}$ stage, insurance status, marital status and median household income.

\section{Proportional Mortality Ratio (PMR)}

PMR, which could exhibit the proportion of each COD properly, was defined as the number of deaths due to a specific cause divided by the number of total deaths. Variable "COD to site record" in the SEER registry was applied to recognize different CODs. CVD mortality includes: diseases of heart (ICD 10=100-109, 111, 113, 120-151), hypertension without heart disease (ICD 10=110, 112), cerebrovascular diseases (ICD $10=160-169$ ), atherosclerosis (ICD 10=170), aortic aneurysm (ICD 10=171), other diseases of arteries, arterioles and capillaries (ICD 10=172-178). We performed PMR analyses in Asian patients, and further 
Table I Basic Characteristics of Patients with ccRCC in the SEER Database (Asian Vs White)

\begin{tabular}{|c|c|c|c|c|}
\hline & Total & White & Asian & $P$ \\
\hline$N$ & 25,145 & 23,559 & 1586 & \\
\hline \multicolumn{5}{|l|}{ Age, year } \\
\hline Median (IQR) & $60.00(52.00,69.00)$ & $60.00(52.00,69.00)$ & $61.00(52.00,70.00)$ & 0.013 \\
\hline Sex, n (\%) & & & & $<0.001$ \\
\hline Male & $15,792(62.80)$ & $14,703(62.4 I)$ & $1089(68.66)$ & \\
\hline Female & $9353(37.20)$ & 8856 (37.59) & $497(31.34)$ & \\
\hline Year of diagnosis, n (\%) & & & & 0.802 \\
\hline 2010 & $3479(13.84)$ & $3273(13.89)$ & $206(12.99)$ & \\
\hline 2011 & $3720(14.79)$ & $3485(14.79)$ & $235(14.82)$ & \\
\hline 2012 & $4064(16.16)$ & $3804(16.15)$ & $260(16.39)$ & \\
\hline 2013 & $4237(16.85)$ & $3980(16.89)$ & $257(16.2)$ & \\
\hline 2014 & $4630(|8.4|)$ & $4322(18.35)$ & $308(19.42)$ & \\
\hline 2015 & $5015(19.94)$ & 4695 (19.93) & $320(20.18)$ & \\
\hline Laterality, n (\%) & & & & 0.057 \\
\hline Left & $12,339(49.07)$ & II,524 (48.92) & $815(51.39)$ & \\
\hline Right & $12,806(50.93)$ & $12,035(51.08)$ & $77 I(48.6 I)$ & \\
\hline Histological stage, n (\%) & & & & 0.134 \\
\hline Localized & I8,042 (7I.75) & I6,878 (7I.64) & $1164(73.39)$ & \\
\hline Regional & $4612(18.34)$ & 4351 (18.47) & $261(16.46)$ & \\
\hline Distant & $249 \mid(9.91)$ & $2330(9.89)$ & $161(10.15)$ & \\
\hline Tumor Grade ${ }^{\mathrm{a}}, \mathrm{n}(\%)$ & & & & 0.369 \\
\hline I-II & 14,057 & $13,173(55.9 \mid)$ & $884(55.74)$ & \\
\hline III-IV & 7990 & 7468 (3I.7) & $522(32.91)$ & \\
\hline Unknown & 3098 & $2918(12.39)$ & $180(11.35)$ & \\
\hline T stage, $\mathrm{n}(\%)$ & & & & 0.503 \\
\hline TI & $|6,35|(65.03)$ & 15,297 (64.93) & $1054(66.46)$ & \\
\hline $\mathrm{T} 2$ & $2679(10.65)$ & $2509(10.65)$ & $170(10.72)$ & \\
\hline $\mathrm{T} 3$ & $5667(22.54)$ & $5329(22.62)$ & $338(2 \mid .3 I)$ & \\
\hline T4 & $448(1.78)$ & $424(1.8)$ & $24(\mathrm{I} .5 \mathrm{I})$ & \\
\hline $\mathrm{N}$ stage, n (\%) & & & & 0.629 \\
\hline No & $24,201(96.25)$ & $22,67 \mid(96.2307)$ & $1530(96.47)$ & \\
\hline $\mathrm{NI}$ & $944(3.75)$ & $888(3.7693)$ & $56(3.53)$ & \\
\hline M stage, n (\%) & & & & 0.767 \\
\hline Mo & $22,678(90.19)$ & $21,25 \mid(90.2)$ & I 427 (89.97) & \\
\hline MI & $2467(9.8 I)$ & $2308(9.8)$ & $159(10.03)$ & \\
\hline Median household income, $\mathrm{n}(\%)$ & & & & $<0.001$ \\
\hline Low & $12,832(5 \mid .03)$ & I2,334 (52.35) & $498(31.40)$ & \\
\hline $\mathrm{High}^{\mathrm{b}}$ & $12,3 \mid 3(48.97)$ & II,225 (47.65) & $1088(68.60)$ & \\
\hline Marital status, n (\%) & & & & $<0.001$ \\
\hline Never married & $3890(15.47)$ & $3686(15.65)$ & $204(12.86)$ & \\
\hline Married & $16,705(66.43)$ & $15,529(65.92)$ & $1176(74.15)$ & \\
\hline SDW & $4550(18.10)$ & $4344(18.43)$ & $206(12.99)$ & \\
\hline Insurance status, n (\%) & & & & $<0.001$ \\
\hline Any Medicaid & 3001 (11.93) & $2760(11.71)$ & $24 \mid(15.2)$ & \\
\hline Insured & $21,390(85.07)$ & $20,083(85.25)$ & I $307(82.4 \mid)$ & \\
\hline
\end{tabular}

(Continued) 
Table I (Continued).

\begin{tabular}{|l|c|c|c|c|}
\hline & Total & White & Asian & $P$ \\
\hline Uninsured & $754(3.00)$ & $716(3.04)$ & $38(2.39)$ & \\
\hline $\begin{array}{l}\text { Surgery, n (\%) } \\
\text { No }\end{array}$ & $1244(4.95)$ & $1174(4.98)$ & $70(4.41)$ & 0.311 \\
Yes & $23,901(95.05)$ & $22,385(95.02)$ & $1516(95.59)$ & \\
\hline
\end{tabular}

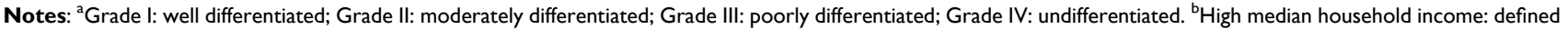
by earnings above the median value in this sample.

Abbreviations: ccRCC, clear cell renal cell carcinoma; SEER, Surveillance Epidemiology and End Results; IQR, interquartile range; SDW, separated, divorced or widowed.

stratified by race ethnicity, age, sex, tumor laterality, histological stage, median household income, marital status, insurance status and surgery. Finally, comparison between Asian and White patients in PMRs was developed.

\section{Survival Outcomes}

In Asian patients, Kaplan-Meier (KM) analyses were performed to explore the long-term prognosis. Racial disparities between Asian and White patients were then compared. Furthermore, we developed subgroup analyses stratified by clinical variables. Similarly, KM analyses were performed in the PSM patients. Moreover, the 3- and 5-year OS/ cancer-specific survival (CSS) probabilities were calculated for subsequent comparisons. Lastly, a competing risk regression model was built to explore the prognostic factors of CSS in ccRCC patients, while deaths from other causes were regard as competing events.

\section{Statistical Analyses}

Continuous variables were displayed in the form of median (interquartile range, IQR) and compared using MannWhitney U or Kruskal-Wallis test. Categorical variables were presented in the form of $\mathrm{n}(\%)$, and Chi-square test or Fisher's exact test was utilized to explore the statistical significance in proportion differences. PSM analysis was performed to balance the basic characteristics. Racial disparities in survival outcomes were compared utilizing KM analyses. Competing risk regression model was applied to identify prognostic factors for CSS in ccRCC patients. In this study, statistical analyses were produced using SPSS 23.0 software (SPSS Inc, Chicago, IL, USA) and $\mathrm{R}$ software (V3.4.1). A two-sided $\mathrm{P}<0.05$ was statistically significant.

\section{Results \\ Clinical Characteristics}

A total of 1586 Asian patients were eventually enrolled in our study. As shown in Table 1, the median (IQR) age at diagnosis was $61(52-70)$ years old. Most patients were male $(68.66 \%)$, older $(>45: 88.52 \%)$, married $(74.15 \%)$, insured (82.41\%), with earlier tumor stage (T1: 66.46\%), grade (grade I-II: $66.46 \%$ ) and higher median household income $(68.60 \%)$. In addition, most diseases were localized (73.39\%) without lymph node (N0: $96.47 \%$ ) or distant metastasis (M0: 89.97\%), and surgery was performed in $95.59 \%$ of Asian patients.

In Table 2, subsequent analyses based on race/ethnicity in Asian-American patients revealed that patients from South Asian had the youngest age at diagnosis (median: 56 years old), while Japanese patients had the oldest age at diagnosis (median: 65 years old). Moreover, Japanese patients had the highest proportion of insured patients (94.71\%) and the lowest proportion of married patients $(67.72 \%)$ than other populations. In tumor characteristics, patients from South Asian seemed to have the earliest stage of diseases (localized: $76.83 \%, \mathrm{~T} 1: 70.73 \%$ ) than other ethnicities.

Compared with White patients (Table 1), Asian patients had a higher proportion of male $(68.66 \%$ vs $62.41 \%, \mathrm{P}<0.001)$ and high level of median household income ( $68.60 \%$ vs $47.65 \%, \mathrm{P}<0.001)$. Moreover, the proportions of insured patients $(85.25 \%)$ and never married or SDW $(34.08 \%)$ patients in Whites were significantly higher than Asians.

\section{PMR}

A total of $228(14.38 \%)$ Asian patients died up to the last follow-up, including 175 (76.75\%) patients died of cancer itself, 28 (12.28\%) patients died of CVD and 25 (10.96\%) patients died of other causes (Figure 2). Subsequently, we 
Table 2 Basic Characteristics of Asian Patients with ccRCC in the SEER Database, Stratified by Race/Ethnicity

\begin{tabular}{|c|c|c|c|c|c|}
\hline & Chinese & Japanese & South Asian & Other Asian & $\boldsymbol{P}$ \\
\hline $\mathrm{N}$ & 274 & 189 & 164 & 959 & \\
\hline \multicolumn{6}{|l|}{ Age, year or n (\%) } \\
\hline Median (IQR) & $64.00(54.00,72.75)$ & $65.00(55.00,74.00)$ & $56.00(46.00,65.00)$ & $61.00(52.00,69.00)$ & $<0.0001$ \\
\hline$<45$ & $24(8.76)$ & $13(6.88)$ & $39(23.78)$ & $106(11.05)$ & $<0.0001$ \\
\hline $45-65$ & $119(43.43)$ & 78 (4I.27) & 81 (49.39) & $487(50.78)$ & \\
\hline$>65$ & $|3|(47.8 \mid)$ & $98(51.85)$ & $44(26.83)$ & $366(38.16)$ & \\
\hline Sex, n (\%) & & & & & 0.2506 \\
\hline Male & $193(70.44)$ & I35 (7|.43) & $120(73.17)$ & $64 I(66.84)$ & \\
\hline Female & 81 (29.56) & $54(28.57)$ & $44(26.83)$ & $318(33.16)$ & \\
\hline Year of diagnosis, n (\%) & & & & & 0.2303 \\
\hline 2010 & $33(12.04)$ & 27 (I4.29) & $23(14.02)$ & $123(12.83)$ & \\
\hline 2011 & 41 (14.96) & 34 (I7.99) & $28(\mid 7.07)$ & $132(13.76)$ & \\
\hline 2012 & $5 I(I 8.6 I)$ & $29(15.34)$ & $18(10.98)$ & $162(16.89)$ & \\
\hline 2013 & $35(12.77)$ & $29(15.34)$ & $27(16.46)$ & $166(17.31)$ & \\
\hline 2014 & $53(19.34)$ & $40(21.16)$ & $24(14.63)$ & 191 (19.92) & \\
\hline 2015 & 61 (22.26) & $30(15.87)$ & $44(26.83)$ & 185 (19.29) & \\
\hline Laterality, n (\%) & & & & & 0.4997 \\
\hline Left & I36 (49.64) & 89 (47.09) & $85(51.83)$ & $505(52.66)$ & \\
\hline Right & $138(50.36)$ & $100(52.91)$ & $79(48.17)$ & $454(47.34)$ & \\
\hline Histological stage, n (\%) & & & & & 0.0422 \\
\hline Localized & $208(75.91)$ & $119(62.96)$ & $126(76.83)$ & $711(74.14)$ & \\
\hline Regional & $4 \mid(\mid 4.96)$ & $45(23.81)$ & $24(14.63)$ & I5I (15.75) & \\
\hline Distant & $25(9.12)$ & $25(13.23)$ & I 4 (8.54) & $97(10.11)$ & \\
\hline Tumor Grade ${ }^{\mathrm{a}}, \mathrm{n}(\%)$ & & & & & 0.0135 \\
\hline I-II & $169(61.68)$ & $106(56.08)$ & $85(51.83)$ & $524(54.64)$ & \\
\hline III-IV & 81 (29.56) & $73(38.62)$ & $58(35.37)$ & $310(32.33)$ & \\
\hline Unknown & $24(8.76)$ & $10(5.29)$ & $21(12.80)$ & $125(13.03)$ & \\
\hline T stage, n (\%) & & & & & 0.0447 \\
\hline $\mathrm{TI}$ & I85 (67.52) & $112(59.26)$ & 116 (70.73) & $64 I(66.84)$ & \\
\hline $\mathrm{T} 2$ & $32(\mathrm{II} .68)$ & $15(7.94)$ & $14(8.54)$ & 109 (11.37) & \\
\hline $\mathrm{T} 3$ & $52(18.98)$ & $60(31.75)$ & $33(20.12)$ & $193(20.13)$ & \\
\hline $\mathrm{T} 4$ & $5(1.82)$ & $2(1.06)$ & $\mathrm{I}(0.6 \mathrm{I})$ & $16(1.67)$ & \\
\hline N stage, n (\%) & & & & & 0.7286 \\
\hline No & $267(97.45)$ & I8I (95.77) & $157(95.73)$ & $925(96.45)$ & \\
\hline $\mathrm{NI}$ & $7(2.55)$ & $8(4.23)$ & $7(4.27)$ & $34(3.55)$ & \\
\hline M stage, n (\%) & & & & & 0.3624 \\
\hline Mo & $249(90.88)$ & I 64 (86.77) & I5I (92.07) & $863(89.99)$ & \\
\hline MI & $25(9.12)$ & $25(13.23)$ & $13(7.93)$ & $96(10.01)$ & \\
\hline \multicolumn{6}{|c|}{ Median household income, n (\%) } \\
\hline Low & I 38 (50.36) & $153(80.95)$ & $66(40.24)$ & I 38 (50.36) & \\
\hline $\mathrm{High}^{\mathrm{b}}$ & $136(49.64)$ & $36(19.05)$ & $98(59.76)$ & $136(49.64)$ & \\
\hline Marital status, n (\%) & & & & & $<0.0001$ \\
\hline Never married & $21(7.66)$ & 37 (19.58) & $10(6.10)$ & $136(14.18)$ & \\
\hline Married & $208(75.91)$ & $128(67.72)$ & I 42 (86.59) & $698(72.78)$ & \\
\hline SDW & $45(16.42)$ & $24(12.70)$ & $12(7.32)$ & $125(13.03)$ & \\
\hline
\end{tabular}

(Continued) 
Table 2 (Continued).

\begin{tabular}{|c|c|c|c|c|c|}
\hline & Chinese & Japanese & South Asian & Other Asian & $P$ \\
\hline Insurance status, $\mathrm{n}(\%)$ & & & & & $<0.0001$ \\
\hline Any Medicaid & 49 (I7.88) & $7(3.70)$ & $28(I 7.07)$ & 157 (16.37) & \\
\hline Insured & $225(82.12)$ & I 79 (94.7I) & I $28(78.05)$ & $775(80.81)$ & \\
\hline Uninsured & $0(0.00)$ & $3(1.59)$ & $8(4.88)$ & $27(2.82)$ & \\
\hline Surgery, n (\%) & & & & & 0.3485 \\
\hline No & II (4.0I) & $9(4.76)$ & $3(1.83)$ & $47(4.90)$ & \\
\hline Yes & $263(95.99)$ & $180(95.24)$ & 161 (98.17) & $912(95.10)$ & \\
\hline
\end{tabular}

Notes: aGrade I: Well differentiated; Grade II: Moderately differentiated; Grade III: Poorly differentiated; Grade IV: Undifferentiated. bHigh median household income: defined by earnings above the median value in this sample.

Abbreviations: ccRCC, clear cell renal cell carcinoma; SEER, Surveillance Epidemiology and End Results; IQR, interquartile range; SDW, separated, divorced or widowed.

performed PMR analyses in Asian patients further stratified by race/ethnicity (Figure $3 \mathrm{~A}$ ), age at diagnosis (Figure 3B), sex (Figure 3C), tumor laterality (Figure 3D), histological stage (Figure 3E), median household income (Figure 3F), marital status (Figure 3G), insurance status (Figure $3 \mathrm{H}$ ) and the administration of surgery (Figure 3I).

In Asian populations, the PMRs of different CODs were similar in different races, without statistical difference $(\mathrm{P}=0.767$, Table 3 and Figure 3). The PMR of ccRCC in patients $\leq 65$ years old was significantly higher than that in patients $>65$ years old $(90.11 \%$ vs $67.88 \%)$, while the PMR of CVD was significantly lower in patients $\leq 65$ years old
(3.30\% vs $18.25 \%)$. Moreover, as the disease progressed, the proportion of patients who died of ccRCC $(58.46 \%$ vs $70.18 \%$ vs $91.51 \%$ ) increased gradually, while the proportion of patients who died of CVD (21.54\% vs $14.04 \%$ vs $5.66 \%)$ and other causes $(20.00 \%$ vs $15.79 \%$ vs $2.83 \%)$ decreased. In addition, the administration of surgery could reduce the risk of dying from ccRCC significantly (89.80\% vs.73.18\%). However, sex, tumor laterality, median household income, marital status and insurance status seemed to have no significant effect on the PMRs of different CODs.

Similarly, there were 3908 (16.59\%) White patients died up to the last follow-up, including 2785 (71.26\%) patients died of ccRCC, 521 (13.33\%) patients died of CVD and 602

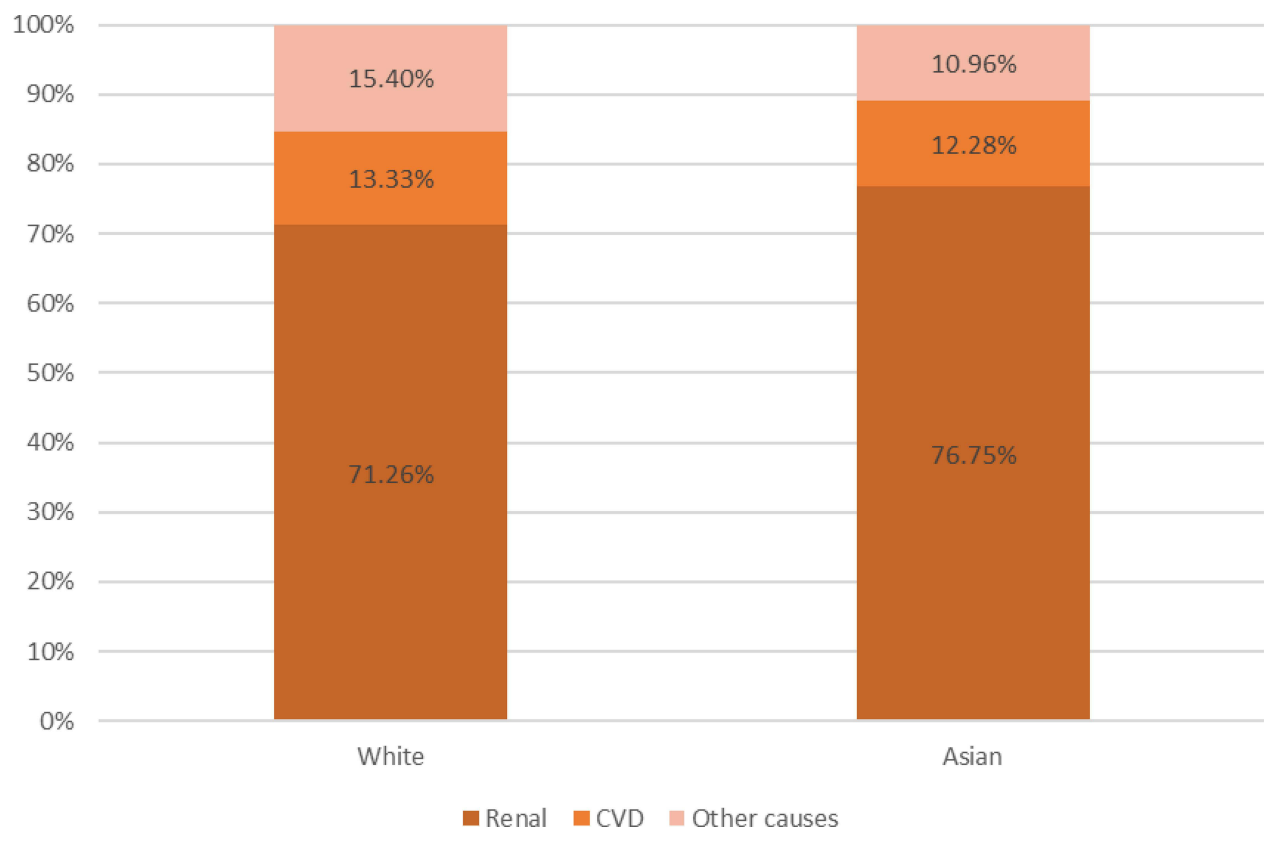

Figure 2 Proportional mortality ratios of different CODs (renal cancer vs CVD vs other causes) in Asian-American and White patients with ccRCC. Abbreviations: COD, causes of death; CVD, cardiovascular diseases; ccRCC, clear cell renal cell carcinoma. 


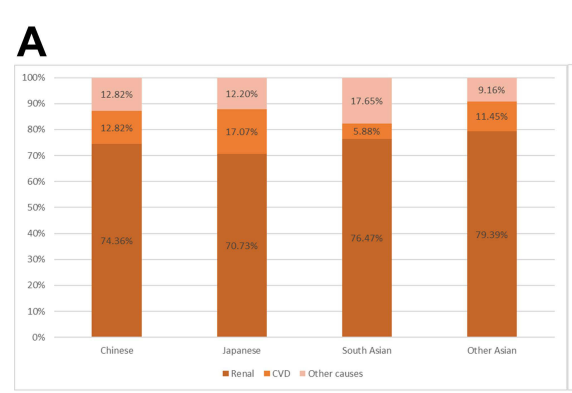

B
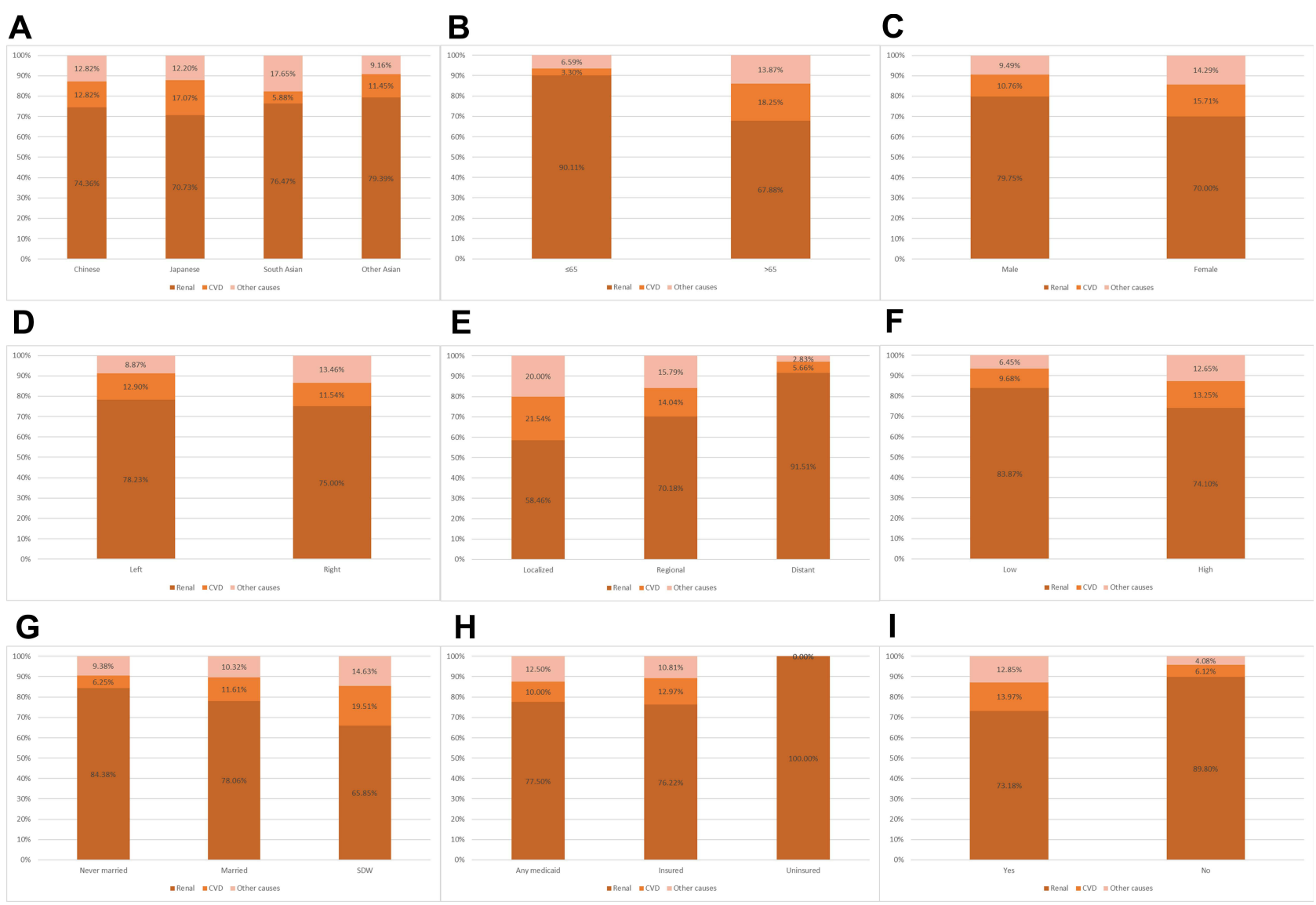

Figure 3 Proportional mortality ratios of different CODs in Asian patients with ccRCC, stratified by race/ethnicity (A), age at diagnosis (B), sex (C), tumor laterality (D), historic stage (E), median household income $(\mathbf{F})$, marital status $(\mathbf{G})$, insurance status $(\mathbf{H})$ and the administration of surgery $(\mathbf{I})$.

Abbreviations: COD, causes of death; ccRCC, clear cell renal cell carcinoma.

(15.04\%) patients died of other causes. No significant differences were detected between Asian and White patients in PMRs of different CODs ( $\mathrm{P}=0.143$, Figure 2).

\section{Survival Outcomes}

In the whole population, the last follow-up time was December 31, 2017, and the median follow-up was 35 (IQR: 19-55) months. The 5-year OS and CSS rates of Asian patients were $81.2 \%$ and $85.9 \%$, respectively. As shown in Figures 4 and 5, in Asian populations, Japanese patients (5-year OS: $74.0 \%, 95 \% \mathrm{CI}=66.9-82.0 \%$ ) had the worst OS while those from South Asian (5-year OS: 85.5\%, 95\% CI $=78.6-93.0 \%$ ) had the best OS (Figure 4A). Moreover, younger age (Figures 4B and 5B), earlier stage of disease [histological stage (Figures $4 \mathrm{C}$ and $5 \mathrm{C}$ ), TNM stage (Figures $4 \mathrm{D}-\mathrm{F}$ and $5 \mathrm{D}-\mathrm{F}$ ), and surgery (Figures $4 \mathrm{G}$ and 5G)] were tightly associated with better OS and CSS in Asian patients. However, tumor laterality (Figures $4 \mathrm{H}$ and 5H) and sex (Figures 4I and 5I) were not related to survival outcomes significantly.
Before PSM, no significant differences were detected in OS and CSS between Asian and White patients (Figure 6A and B), and further subgroup analyses stratified by clinical variables revealed the same results (Tables $\mathrm{S} 1$ and $\underline{\mathrm{S} 2}$ ). Furthermore, PSM analyses were conducted to balance the basic characteristics between Asian and White patients (Table S3). In addition, comparable survival outcomes were detected in patients after PSM (Figure 6C and D, Tables S4-S5).

Lastly, competing risk regression model found that age at diagnosis $(\mathrm{P}<0.001)$, tumor grade $(\mathrm{P}<0.001)$, histological stage $(\mathrm{P}<0.001)$, median household income $(\mathrm{P}<0.001)$ and the administration of surgery $(\mathrm{P}<0.001)$ were prognostic factors for CSS in ccRCC patients, while died of other causes was regarded as a competing event (Table 4).

\section{Discussion}

In our study, we investigated the basic characteristics, PMRs and long-term survival outcomes of AsianAmerican patients with ccRCC, and made comparisons 
Table 3 Proportional Mortality Ratios of Different Causes of Death in Asian Patients with ccRCC

\begin{tabular}{|c|c|c|c|c|c|}
\hline & Total & Renal & CVD & Other Causes & $P$ value \\
\hline Total & 228 & I75 (76.74) & $28(12.28)$ & $25(10.96)$ & \\
\hline Race & & & & & 0.767 \\
\hline Chinese & 39 & $29(74.36)$ & $5(12.82)$ & $5(12.82)$ & \\
\hline Japanese & 41 & $29(70.73)$ & $7(17.07)$ & $5(12.20)$ & \\
\hline South Asian & 17 & $13(76.47)$ & I (5.88) & $3(17.65)$ & \\
\hline Other Asian & $|3|$ & $104(79.39)$ & I5 (II.45) & $12(9.16)$ & \\
\hline Age & & & & & $<0.001$ \\
\hline$<65$ & 91 & $82(90.11)$ & $3(3.30)$ & $6(6.59)$ & \\
\hline$>65$ & 137 & $93(67.88)$ & $25(\mid 8.25)$ & $19(13.87)$ & \\
\hline Sex & & & & & 0.274 \\
\hline Male & 158 & I $26(79.75)$ & $17(10.76)$ & I5 (9.49) & \\
\hline Female & 70 & $49(70.00)$ & II (I5.7I) & $10(14.29)$ & \\
\hline Laterality & & & & & 0.535 \\
\hline Left & 124 & 97 (78.23) & $16(12.9)$ & II (8.87) & \\
\hline Right & 104 & $78(75.00)$ & $12(11.54)$ & $14(13.46)$ & \\
\hline Histological stage & & & & & $<0.001$ \\
\hline Localized & 65 & $38(58.46)$ & $14(21.54)$ & $13(20.00)$ & \\
\hline Regional & 57 & $40(70.18)$ & $8(14.04)$ & $9(15.79)$ & \\
\hline Distant & 106 & 97 (9I.5I) & $6(5.66)$ & $3(2.83)$ & \\
\hline Median household income & & & & & $0.27 I$ \\
\hline Low & 62 & $52(83.87)$ & $6(9.68)$ & $4(6.45)$ & \\
\hline $\mathrm{High}^{\mathrm{a}}$ & 166 & $123(74.10)$ & $22(13.25)$ & $21(12.65)$ & \\
\hline Marital status & & & & & 0.373 \\
\hline Never married & 32 & 27 (84.38) & $2(6.25)$ & $3(9.38)$ & \\
\hline Married & 155 & I2I (78.06) & $18(11.61)$ & $16(10.32)$ & \\
\hline SDW & 41 & 27 (65.85) & $8(19.51)$ & $6(14.63)$ & \\
\hline Insurance status & & & & & 0.942 \\
\hline Any Medicaid & 40 & 31 (77.50) & $4(10.00)$ & $5(12.50)$ & \\
\hline Insured & 185 & I4I (76.22) & 24 (I2.97) & $20(\mid 0.8 I)$ & \\
\hline Uninsured & 3 & $3(100.00)$ & $0(0.00)$ & $0(0.00)$ & \\
\hline Surgery & & & & & 0.050 \\
\hline No & 49 & $44(89.80)$ & $3(6.12)$ & $2(4.08)$ & \\
\hline Yes & 179 & $13 \mid(73.18)$ & 25 (13.97) & $23(12.85)$ & \\
\hline
\end{tabular}

Notes: ${ }^{2}$ High median household income: defined by earnings above the median value in this sample CVD = cardiovascular disease; SDW = separated, divorced or widowed. CVD mortality includes: diseases of heart $(I C D 10=100-109,111,113,120-151)$, hypertension without heart disease $(I C D I 0=110$, II2), cerebrovascular diseases $(I C D$ $10=160-169)$, atherosclerosis $(I C D 10=170)$, aortic aneurysm $(I C D 10=171)$, other diseases of arteries, arterioles and capillaries $(I C D I 0=172-I 78)$.

with White patients. There are many histological subtypes of kidney cancer, mainly including ccRCC, collecting duct RCC, papillary RCC, chromophobe RCC, each of which has a unique molecular structure. ccRCC is the most common subtype, accounting for approximately threefourths of kidney cancer. ${ }^{3,19}$ In addition, different subtypes of RCC have been prove to exhibit different survival outcomes, ${ }^{20-22}$ and there may be a large selection bias in the analysis of mixed tumors of different histological types. In Asian populations, Japanese patients with ccRCC had the highest proportion of insured patients (94.71\%) and lowest proportion of married patients (67.72\%) than other populations. In tumor characteristics, patients from South Asian seemed to have the earliest stage diseases than other ethnicities. Older age at diagnosis, earlier stage and surgery were tightly associated with a lower risk of dying of RCC. Asian patients had higher age at diagnosis and comparable tumor characteristics 


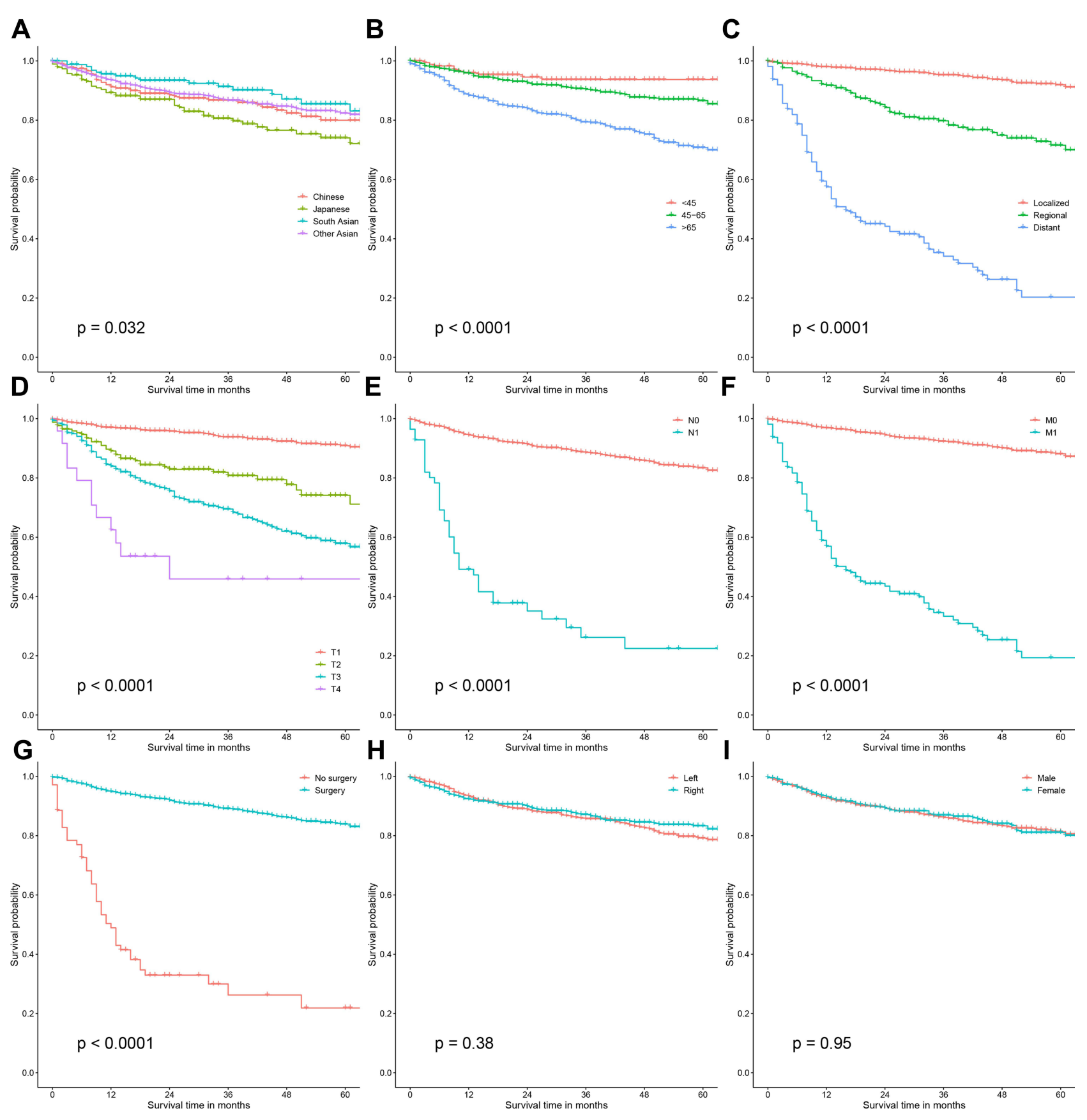

Figure 4 Kaplan-Meier curves of OS in Asian-patients with ccRCC, stratified by race/ethnicity (A), age at diagnosis (B), historic stage (C), T stage (D), N stage (E), M stage $(\mathbf{F})$, the administration of surgery $(\mathbf{G})$, tumor laterality $(\mathbf{H})$ and sex $(\mathbf{I})$. Younger age at diagnosis, earlier tumor stages (TNM, histological) and the administration of surgery were tightly associated with better OS in Asian-American patients.

Abbreviations: ccRCC, clear cell renal cell carcinoma; OS, overall survival.

when compared with White patients. Lastly, comparisons in survival outcomes between Asian and White patients were not statistically different.

Competing risk regression model revealed that younger age, earlier histological stage, earlier tumor grade, higher median household income and the administration of surgery were tightly associated with better CSS in ccRCC patients. Previous studies have confirmed the potential prognostic value of these variables in RCC patients. ${ }^{23-25}$ In our study, we performed a competing risk regression model to explore the potential prognostic factors rather than a Cox regression model, since the vast majority of patients included in the current work harbor organconfined disease. Therefore, cancer-specific mortality is 


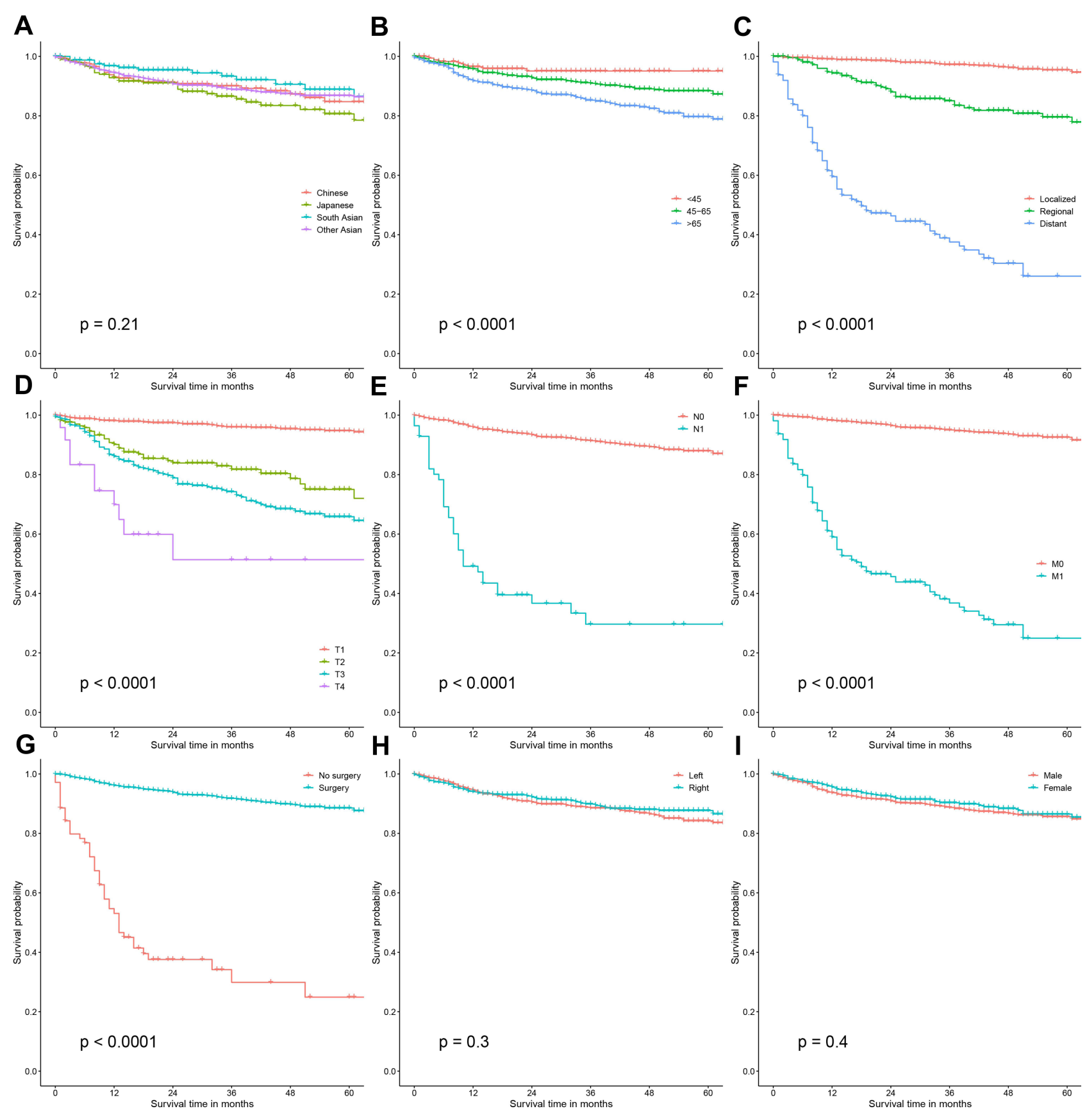

Figure 5 Kaplan-Meier curves of CSS in Asian-American patients with ccRCC, stratified by race/ethnicity (A), age at diagnosis (B), historic stage (C), T stage (D), N stage $(\mathbf{E})$, $M$ stage $(\mathbf{F})$, the administration of surgery $(\mathbf{G})$, tumor laterality $(\mathbf{H})$ and sex $(\mathbf{I})$. Younger age at diagnosis, earlier tumor stages $(\mathrm{TNM}$, histological) and the administration of surgery were tightly associated with better CSS in Asian-American patients.

Abbreviations: ccRCC, clear cell renal cell carcinoma; CSS, cancer-specific survival.

similar, if not inferior, to other-cause mortality. We found that race/ethnicity was not a significant risk factor for survival outcomes after adjusting clinical variables. Similarly, Zhou et al constructed prognostic nomograms for CSS and OS in patients with kidney cancer on the basis of the SEER database, and they found that race was not a prognostic factor for OS and CSS. In Chinese population, Zhu et $\mathrm{al}^{26}$ found that age at diagnosis, Eastern Cooperative Oncology Group (ECOG) score, preoperative platelet, neutrophil-to-lymphocyte ratio (NLR), tumor size, Fuhrman nuclear grade and $\mathrm{T}$ stage were independent risk factors for recurrence-free survival in ccRCC patients who underwent (partial) nephrectomy. However, some variables were missing in the SEER 
A
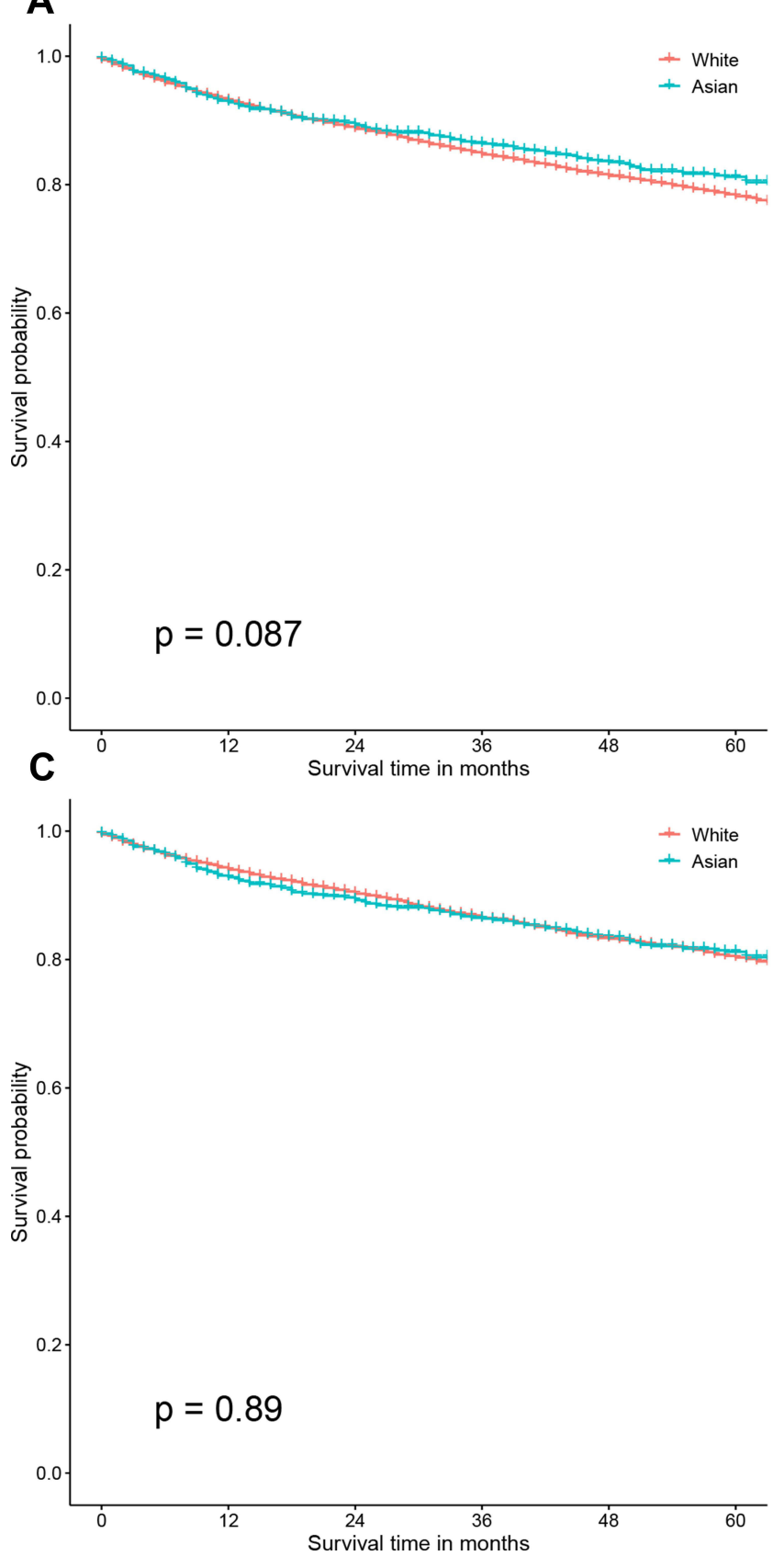

B
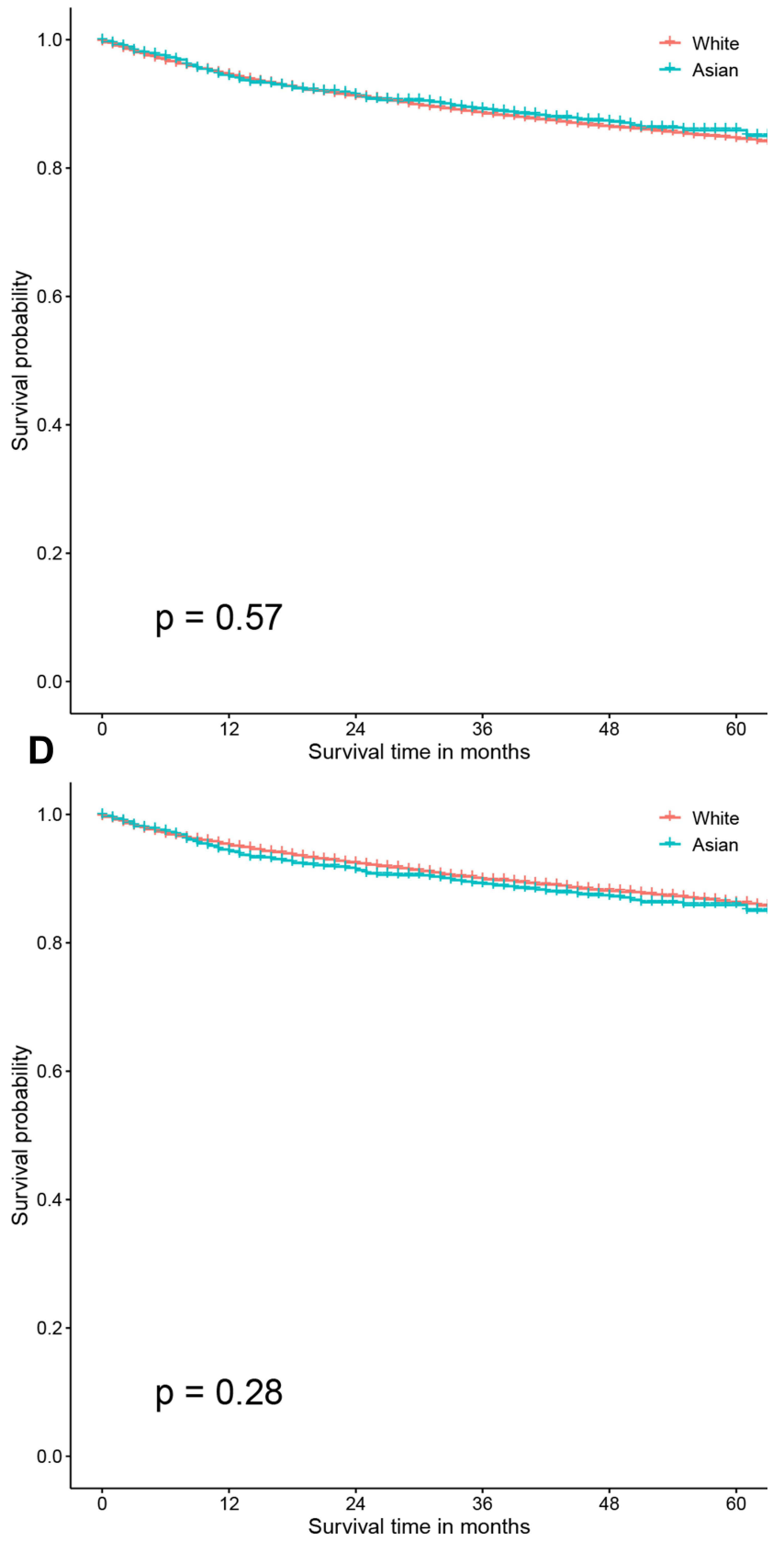

Figure 6 Kaplan-Meier curves of survival outcomes in Asian and White patients with ccRCC. OS before PSM (A), CSS before PSM (B), Asian American patients had comparable OS and CSS when compared with White patients before PSM. OS after PSM (C) and CSS after PSM (D), Asian American patients had comparable OS and CSS when compared with White patients after PSM.

Abbreviations: ccRCC, clear cell renal cell carcinoma; OS, overall survival; CSS, cancer-specific survival; PSM, propensity score matching.

database, such as ECOG score and gene expression, which made the prediction model a little insufficient.

Many studies have investigated the racial disparities in RCC patients in incidence rates basic characteristics and survival outcomes. Among American men in 2014, Black men were the most probably to suffer from renal and pelvic cancer $(24.7 / 100,000)$, followed by White men
$(22.0 / 100,000) .{ }^{27}$ In addition, the distributions of histological subtypes in different races were also different. Previous studies have revealed that ccRCC was more common in Whites while Black patients were more likely to get pRCC. $^{28,29}$ Chow et al ${ }^{10}$ found that White patients with RCC had better prognosis than Black patients, and similar survival trends were detected in subgroup analyses 
Table 4 Competing Risk Regression Model for Predicting Cancer-Specific Survival in ccRCC Patients

\begin{tabular}{|c|c|c|c|}
\hline Variable & HR & $95 \% \mathrm{Cl}$ & $P$ value \\
\hline \multicolumn{4}{|l|}{ Race } \\
\hline Asian & Reference & & \\
\hline White & 0.961 & $0.802-1.150$ & 0.662 \\
\hline Age & 1.015 & $1.012-1.020$ & $<0.001$ \\
\hline \multicolumn{4}{|l|}{ Sex } \\
\hline Male & Reference & & \\
\hline Female & 1.008 & $0.922-1.101$ & 0.866 \\
\hline \multicolumn{4}{|l|}{ Laterality } \\
\hline Left & Reference & & \\
\hline Right & 0.986 & $0.912-1.066$ & 0.721 \\
\hline \multicolumn{4}{|l|}{ Grade } \\
\hline Grade I-II & Reference & & \\
\hline Grade III-IV & 2.569 & $2.317-2.849$ & $<0.001$ \\
\hline Unknown & 1.674 & $1.464-1.914$ & $<0.001$ \\
\hline \multicolumn{4}{|l|}{ Histological stage } \\
\hline Localized & Reference & & \\
\hline Regional & 4.452 & $3.963-5.003$ & $<0.001$ \\
\hline Distant & 21.156 & $18.882-23.704$ & $<0.001$ \\
\hline \multicolumn{4}{|l|}{ Marital status } \\
\hline Never married & Reference & & \\
\hline Married & 0.914 & $0.807-1.034$ & 0.152 \\
\hline SDW & 1.089 & $0.942-1.258$ & 0.251 \\
\hline \multicolumn{4}{|l|}{ Median household income } \\
\hline Low & Reference & & \\
\hline High & 0.838 & $0.775-0.907$ & $<0.001$ \\
\hline \multicolumn{4}{|l|}{ Insurance status } \\
\hline Any Medicaid & Reference & & \\
\hline Insured & 0.899 & $0.790-1.022$ & 0.104 \\
\hline Uninsured & 1.117 & $0.882-1.416$ & 0.359 \\
\hline \multicolumn{4}{|l|}{ Surgery } \\
\hline No & Reference & & \\
\hline Yes & 0.311 & $0.272-0.355$ & $<0.001$ \\
\hline
\end{tabular}

Abbreviations: HR, hazard ratio; $\mathrm{Cl}$, confidence interval; SDW, separated, divorced or widowed.

stratified by clinical variables. However, no studies that have comprehensively explored the clinical characteristics and prognosis of ccRCC in Asian populations. In our study, Asian patients had a higher proportion of male and higher household income when compared with White patients. However, no significant differences were found in survival outcomes between Asian and White patients before and after PSM. Jivanji et $\mathrm{al}^{30}$ demonstrated that
Black patients had the best 5-year OS than other races, while those from American Indian/AK Native suffered the worst prognosis. However, they did not make further survival analyses between Asian and White patients. Moreover, in the adjusted COX regression model, they concluded that race was not a significant risk factor for 5 -year CSS in ccRCC patients (Asian/Pacific Islander to White: Hazard Ratio $=0.99,95 \% \mathrm{CI}=0.82-1.20$ ).

Nowadays, cancer and CVD have been the two leading CODs worldwide. There are many similar risk factors between CVD and cancer occurrence (including obesity, smoking, diabetes, etc.), and there may be shared biological mechanisms between the two. ${ }^{31}$ In recent years, advances in medical treatment have also improved the prognosis of cancer patients, which has also increased the risk of CVD in cancer survivors. Additionally, some treatment methods and drugs for cancer patients are closely related to the risk of CVD. ${ }^{32}$ Some CVD-related factors, including smoking, hypertension and obesity, have already been recognized as risk factors for RCC. ${ }^{33,34}$ In PMR analyses, $12.28 \%$ of Asian patients and $13.33 \%$ of White patients were died of CVD. We found that older age and earlier stage and surgery were closely related to a higher risk of dying of CVD. Clearly, age is one of the most important risk factors leading to CVD. North et $\mathrm{al}^{35}$ investigated the role of lifespan-related gene in regulating cardiovascular health. Moreover, earlier stage of diseases and the administration of surgery may represent better survival outcomes in RCC patients. Lastly, the proportion of different CODs was not different between White and Asian patients.

To our knowledge, previous studies on racial disparities in RCC patients mostly focused on Whites and Blacks. Our study comprehensively explored the basic characteristics, PMR, and survival outcomes of ccRCC in Asian patients through a population-based, large sample sized database for the first time, and made comparisons with White patients. However, there were some limitations that could not be ignored in our research. First, we cannot completely separate the incidence rate of Asian from Pacific Islander due to the design of SEER database itself. Therefore, comparisons between Whites and Asians in incidence rate could not be performed accurately. Secondly, some important data were missing in the SEER database, such as lifestyle (smoking, drinking, body mass index, ECOG score), genomics data, and other therapies (immunotherapy, targeted therapy, etc.), which made it difficult to build an accurate prediction model. 
Finally, it is a retrospective, database-based study with unavoidable selection bias. In the future, well-designed and prospective studies are essential to verify our results.

\section{Conclusion}

Our study comprehensively analyzed the basic characteristics, PMR and survival outcomes of Asian Americans with ccRCC. Asian patients had comparable tumor characteristics and survival outcomes when compared with White patients. In Asian patients, those from South Asian had the youngest age at diagnosis and the earliest stage of diseases. Age, grade, histological stage, household income and surgery were considered to be prognostic factors for CSS. In the future, prospective and well-designed studies are needed to verify our findings. Our study may provide important value for the diagnosis and treatment of ccRCC patients while further studies are needed to verify our findings.

\section{Data Sharing Statement}

All data included in this study are available on reasonable request from the corresponding author.

\section{Ethics Approval and Consent Participate}

The authors are accountable for all aspects of the work in ensuring that questions related to the accuracy or integrity of any part of the work are appropriately investigated and resolved. The study was conducted in accordance with the Declaration of Helsinki (as revised in 2013). All information from the SEER program is available and free for public and approval was obtained from the Ethics Committee of Jiangsu Cancer Hospital. We used the SEER database with the username of 10977-Nov2019.

\section{Funding}

The Research Project of Jiangsu Cancer Hospital (ZM202015).

\section{Disclosure}

All authors declare that they have no conflicts of interest for this work.

\section{References}

1. Bray F, Ferlay J, Soerjomataram I, et al. Global cancer statistics 2018: GLOBOCAN estimates of incidence and mortality worldwide for 36 cancers in 185 countries. CA Cancer J Clin. 2018;68:394-424. doi:10.3322/caac. 21492
2. Chow WH, Dong LM, Devesa SS. Epidemiology and risk factors for kidney cancer. Nat Rev Urol. 2010;7:245-257. doi:10.1038/ nrurol.2010.46

3. Jonasch E, Walker CL, Rathmell WK. Clear cell renal cell carcinoma ontogeny and mechanisms of lethality. Nat Rev Nephrol. 2021;17:245-261. doi:10.1038/s41581-020-00359-2

4. Jonasch E, Gao J, Rathmell WK. Renal cell carcinoma. BMJ. 2014;349:g4797. doi:10.1136/bmj.g4797

5. Turajlic S, Swanton C, Boshoff C. Kidney cancer: the next decade. J Exp Med. 2018;215:2477-2479. doi:10.1084/jem.20181617

6. Krishnan B, Rose TL, Kardos J, et al. Intrinsic genomic differences between African American and white patients with clear cell renal cell carcinoma. JAMA Oncol. 2016;2:664-667. doi:10.1001/ jamaoncol.2016.0005

7. Batai K, Harb-de la Rosa A, Lwin A, et al. Racial and ethnic disparities in renal cell carcinoma: an analysis of clinical characteristics. Clin Genitourin Cancer. 2019;17:e195-e202. doi:10.1016/j.clgc.2018.10.012

8. Vaishampayan UN, Do H, Hussain M, et al. Racial disparity in incidence patterns and outcome of kidney cancer. Urology. 2003;62:1012-1017. doi:10.1016/j.urology.2003.07.010

9. Berndt SI, Carter HB, Schoenberg MP, et al. Disparities in treatment and outcome for renal cell cancer among older black and white patients. J Clin Oncol. 2007;25:3589-3595. doi:10.1200/ JCO.2006.10.0156

10. Chow WH, Shuch B, Linehan WM, et al. Racial disparity in renal cell carcinoma patient survival according to demographic and clinical characteristics. Cancer. 2013;119:388-394. doi:10.1002/cncr.27690

11. Eisenberg MS, Leibovich BC, Kim SP. Racial disparity in renal cell carcinoma patient survival according to demographic and clinical characteristics. Cancer. 2013;119:3100. doi:10.1002/cncr.28126

12. Wang G, Hou J, Ma L, et al. Risk factor for clear cell renal cell carcinoma in Chinese population: a case-control study. Cancer Epidemiol. 2012;36:177-182. doi:10.1016/j.canep.2011.09.006

13. Kim H, Inomoto C, Uchida $T$, et al. Verification of the International Society of Urological Pathology recommendations in Japanese patients with clear cell renal cell carcinoma. Int $J$ Oncol. 2018;52:1139-1148. doi:10.3892/ijo.2018.4294

14. Liu X, Peveri G, Bosetti C, et al. Dose-response relationships between cigarette smoking and kidney cancer: a systematic review and meta-analysis. Crit Rev Oncol Hematol. 2019;142:86-93. doi:10.1016/j.critrevonc.2019.07.019

15. Nam GE, Cho KH, Han K, et al. Obesity, abdominal obesity and subsequent risk of kidney cancer: a cohort study of 23.3 million East Asians. Br J Cancer. 2019;121:271-277. doi:10.1038/s41416-0190500-z

16. Kim CS, Han KD, Choi HS, et al. Association of hypertension and blood pressure with kidney cancer risk: a Nationwide Population-Based Cohort Study. Hypertension. 2020;75:1439-1446. doi:10.1161/HYPERTENSIONAHA.120.14820

17. Lenihan DJ, Cardinale DM. Late cardiac effects of cancer treatment. J Clin Oncol. 2012;30:3657-3664. doi:10.1200/JCO.2012.45.2938

18. Sturgeon KM, Deng L, Bluethmann SM, et al. A population-based study of cardiovascular disease mortality risk in US cancer patients. Eur Heart J. 2019;40:3889-3897. doi:10.1093/eurheartj/ ehz766

19. Sanchez-Gastaldo A, Kempf E, Gonzalez Del Alba A, et al. Systemic treatment of renal cell cancer: a comprehensive review. Cancer Treat Rev. 2017;60:77-89. doi:10.1016/j.ctrv.2017.08.010

20. Nocera L, Colla Ruvolo C, Stolzenbach LF, et al. Tumor stage and substage predict cancer-specific mortality after nephrectomy for nonmetastatic renal cancer: histological subtype-specific validation. Eur Urol Focus. 2021. doi:10.1016/j.euf.2021.02.009

21. Keegan KA, Schupp CW, Chamie K, et al. Histopathology of surgically treated renal cell carcinoma: survival differences by subtype and stage. J Urol. 2012;188:391-397. doi:10.1016/j.juro.2012.04.006 
22. Capitanio U, Cloutier V, Zini L, et al. A critical assessment of the prognostic value of clear cell, papillary and chromophobe histological subtypes in renal cell carcinoma: a population-based study. BJU Int. 2009;103:1496-1500. doi:10.1111/j.1464-410X.2008.08259.x

23. Xue J, Chen W, Xu W, et al. Patterns of distant metastases in patients with clear cell renal cell carcinoma-A population-based analysis. Cancer Med. 2021;10:173-187. doi:10.1002/cam4.3596

24. Zhou Y, Zhang R, Ding Y, et al. Prognostic nomograms and Aggtrmmns scoring system for predicting overall survival and cancer-specific survival of patients with kidney cancer. Cancer Med. 2020;9:2710-2722. doi:10.1002/cam4.2916

25. Zhang G, Wu Y, Zhang J, et al. Nomograms for predicting long-term overall survival and disease-specific survival of patients with clear cell renal cell carcinoma. Onco Targets Ther. 2018;11:5535-5544. doi:10.2147/OTT.S171881

26. Zhu Y, Zhao YR, Yang XF, et al. Postoperative prognostic model for patients with clear cell renal cell carcinoma in a Chinese population. Int J Urol. 2019;26:624-629. doi:10.1111/iju.13936

27. Sims JN, Yedjou CG, Abugri D, et al. Racial disparities and preventive measures to renal cell carcinoma. Int J Environ Res Public Health. 2018;15(6):1089. doi:10.3390/ijerph15061089

28. Olshan AF, Kuo TM, Meyer AM, et al. Racial difference in histologic subtype of renal cell carcinoma. Cancer Med. 2013;2:744-749. doi:10.1002/cam4.110
29. Lipworth L, Morgans AK, Edwards TL, et al. Renal cell cancer histological subtype distribution differs by race and sex. BJU Int. 2016;117:260-265. doi:10.1111/bju.12950

30. Jivanji D, Jamieson S, Mallory C, et al. The association between race and 5-year survival in patients with clear cell renal cell carcinoma: a Cohort Study. Urology. 2021;148:185-191. doi:10.1016/j. urology.2020.10.055

31. Koene RJ, Prizment AE, Blaes A, et al. Shared risk factors in cardiovascular disease and cancer. Circulation. 2016;133:1104-1114. doi:10.1161/CIRCULATIONAHA.115.020406

32. Okwuosa TM, Anzevino S, Rao R. Cardiovascular disease in cancer survivors. Postgrad Med J. 2017;93:82-90. doi:10.1136/postgradmedj-2016-134417

33. Capitanio U, Bensalah K, Bex A, et al. Epidemiology of renal cell carcinoma. Eur Urol. 2019;75:74-84. doi:10.1016/j. eururo.2018.08.036

34. Aurilio G, Piva F, Santoni M, et al. The role of obesity in renal cell carcinoma patients: clinical-pathological implications. Int J Mol Sci. 2019;20:5683. doi:10.3390/ijms20225683

35. North BJ, Sinclair DA. The intersection between aging and cardiovascular disease. Circ Res. 2012;110:1097-1108. doi:10.1161/ CIRCRESAHA.111.246876
International Journal of General Medicine

\section{Publish your work in this journal}

The International Journal of General Medicine is an international, peer-reviewed open-access journal that focuses on general and internal medicine, pathogenesis, epidemiology, diagnosis, monitoring and treatment protocols. The journal is characterized by the rapid reporting of reviews, original research and clinical studies

\section{Dovepress}

across all disease areas. The manuscript management system is completely online and includes a very quick and fair peer-review system, which is all easy to use. Visit http://www.dovepress.com/ testimonials.php to read real quotes from published authors. 